\title{
Post-ablation tubal sterilization syndrome following NovaSure endometrial ablation: two case reports
}

\author{
Teresa Tam $\cdot$ Corissa Elgar $\cdot$ Kelly Jirschele • \\ Emily Lombard
}

Received: 27 February 2012 / Accepted: 1 April 2012 / Published online: 25 April 2012

(C) Springer-Verlag 2012

\begin{abstract}
Endometrial ablation procedures are extensively used for the treatment of menorrhagia on premenopausal patients who failed medical therapy. The increasing popularity of safe, effective, less invasive, nonresectoscopic global endometrial ablation procedures could potentially increase the incidence of unusual adverse outcomes. Postablation tubal sterilization (PATSS) is one of these delayed complications, which could be challenging to diagnose. PATSS is a complication that potentially occurs following a global endometrial ablation in women with previous tubal sterilization. PATSS presents as cyclic pelvic pain caused by tubal distention from occult bleeding into the obstructed tubes. Review of the literature shows that majority of PATSS occurred after rollerball resection and ablation. We report two cases of PATSS after NovaSure ${ }^{\circledR}$ radiofrequency endometrial ablation.
\end{abstract}

Keywords Post-ablation tubal sterilization syndrome, PATSS · Novasure · Endometrial ablation · Tubal ligation · Pelvic pain

\section{Case report no. 1}

A 47-year-old woman (gravida 3, para 3) had a 4-year history of cyclic pelvic pain primarily on the left side. Due to a long history of menorrhagia with resulting anemia, in spite of medical therapy, the patient underwent an endometrial ablation in 2007 using NovaSure ${ }^{\circledR}$ radiofrequency

T. Tam $(\bowtie) \cdot$ C. Elgar $\cdot$ K. Jirschele $\cdot$ E. Lombard

Department of Obstetrics and Gynecology,

Resurrection Health Care/St. Joseph Hospital,

2900 N. Lakeshore Drive,

Chicago, IL 60657, USA

e-mail: maria.tam@reshealthcare.org energy (Hologic, USA). The patient had a laparoscopic tubal ligation with bipolar coagulation in 1993 with another provider. The patient was referred by her primary care physician because of the patient's complaints of chronic pelvic pain and severe dysmenorrhea, which started a few months after the Novasure ${ }^{\circledR}$ endometrial ablation. The pelvic ultrasound showed a $2.0-\mathrm{cm}$ left-sided hydrosalpinx, but the right ovary was not identified. The patient had an unremarkable medical and gynecological history.

Physical examination revealed a soft abdomen without rebound or guarding. Bimanual examination showed a normal-size uterus but elicited cervical motion tenderness and bilateral adnexal tenderness primarily on the left side. Her vital signs were stable.

Laboratory results showed a normal white blood cell count and urinalysis. Serum pregnancy test was negative. Genital cultures with gonorrhea and chlamydia were negative.

On laparoscopy, both tubes were approximately $2-0-\mathrm{cm}$ dilated. The uterus and bilateral ovaries appeared normal. The left hydrosalpinx was identified (Fig. 1). Endometrial lesions were absent. Laparoscopic bilateral salpingectomy and pelvic adhesiolysis were performed using Gyrus PKS ${ }^{\mathrm{TM}}$ advanced bipolar forceps.

She was discharged home the same day, and her postoperative course was without incident. The final pathological diagnosis reported bilateral sterile hydrosalpinx.

\section{Case report no. 2}

A 42-year-old woman (gravida 3, para 3) presented to the Emergency Department with complaints of right lower quadrant pain, watery vaginal discharge, fever, and chills. The patient had NovaSure endometrial ablation 6 weeks 


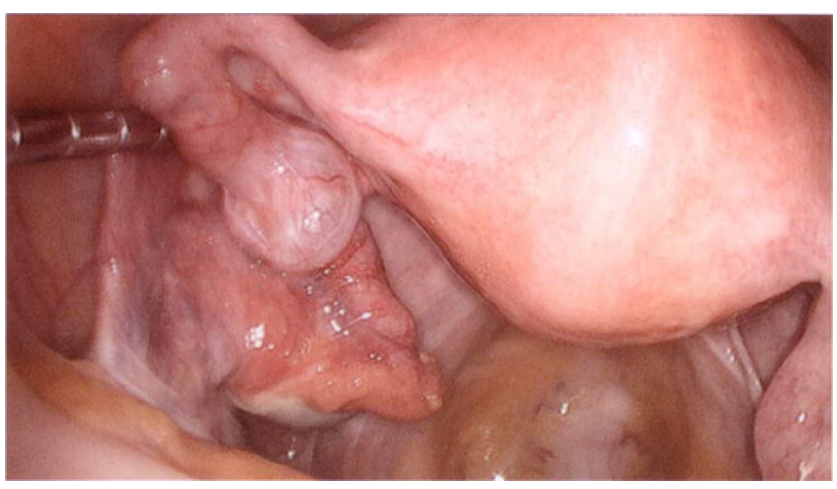

Fig. 1 Left hydrosalpinx on laparoscopy

prior, for a long history of menorrhagia unresponsive to medical therapy. The patient had a history of tubal ligation 5 years prior to endometrial ablation. Her medical and gynecological histories were unremarkable.

Physical examination revealed a benign abdomen. Bimanual examination elicited cervical motion tenderness and bilateral adnexal tenderness primarily on the right side. Vital signs showed a low-grade fever.

Laboratory results showed an elevated white blood cell count of $14 \times 10^{3}$ leukocytes. Serum pregnancy test was negative. Urinalysis was normal. Pelvic ultrasound was unremarkable and showed adequate flow to both ovaries. $\mathrm{CT}$ of the abdomen and pelvis demonstrated mild bilateral hydrosalpinx and findings suggestive of early appendicitis. The patient was admitted for further observation and evaluation. General surgery was primarily consulted by Emergency Department to evaluate for possible appendicitis.

Antibiotics were started. Serial abdominal exams were performed. The final results of gonorrhea and chlamydia cervical cultures were negative. The patient's white blood cell count remained elevated. Her right pelvic pain persisted, accompanied by low-grade fever. The general surgery team performed a laparoscopy for suspected appendicitis.

On laparoscopy, the appendix appeared normal. Bilateral tubal abscesses were noted, and the gynecology team was consulted. Both tubes were densely adhesed, bilaterally engorged, and grossly inflamed. The decision was made to proceed with exploratory laparotomy for adequate dissection. The ovaries and uterus appeared normal. Bilateral salpingectomy was performed.

The patient's postoperative course was uneventful. She remained afebrile and was discharged home on postoperative day 2 , with doxycycline and metronidazole to complete 14 days of treatment.

Table 1 Reported cases of PATSS confirmed by histopathology

\begin{tabular}{|c|c|c|c|c|}
\hline Reference & Authors & $\begin{array}{l}\text { No. of } \\
\text { cases }\end{array}$ & $\begin{array}{l}\text { Endometrial } \\
\text { ablation procedure }\end{array}$ & Management/treatment \\
\hline [1] & Townsend et al. & 6 & Rollerball ablation & $\begin{array}{l}\text { 2-Unilateral salpingectomy } \\
\text { 1-LAVH } \\
\text { 1-Tubal cautery destruction } \\
\text { 3-Bilateral salpingectomy }\end{array}$ \\
\hline [2] & Martin and Inglis & 1 & Rollerball ablation & Laparoscopic monopolar diathermy of tubal stump \\
\hline [3] & Bae et al. & 6 & Rollerball ablation & $\begin{array}{l}\text { 1-TAH/RSO } \\
\text { 2-LAVH } \\
\text { 2-Laparoscopic bilateral salpingectomy } \\
\text { 1-TAH/BSO }\end{array}$ \\
\hline [4] & Webb et al. & 1 & Rollerball ablation & TVH/BSO \\
\hline [5] & McCausland and McCausland & 3 & Rollerball ablation & $\begin{array}{l}\text { 2-Laparoscopic unilateral proximal salpingectomy } \\
\text { and subsequent hysterectomy } \\
\text { 1-TAH/BSO }\end{array}$ \\
\hline [6] & Huang et al. & 1 & Rollerball ablation & Laparoscopic bilateral salpingectomy \\
\hline [7] & Unger and Meeks & 2 & Rollerball ablation & $\begin{array}{l}\text { 1-Hysterectomy } \\
1 \text {-Laparoscopic resection of tubal remnant }\end{array}$ \\
\hline [8] & Turnbull et al. & 2 & Rollerball ablation & 2-Hysterectomy \\
\hline [12] & Chukwujama et al. & 1 & Microwave ablation & Laparoscopic bilateral salpingectomy \\
\hline [13] & Leung and Yuen & 1 & Thermal balloon & Patient declined surgery \\
\hline [11] & Tam et al. & 2 & Radiofrequency electricity & $\begin{array}{l}\text { 1-Exploratory laparotomy with bilateral salpingectomy } \\
\text { 1-Laparoscopic bilateral salpingectomy }\end{array}$ \\
\hline
\end{tabular}

LAVH Laparoscopic-assisted vaginal hysterectomy, TAH total abdominal hysterectomy, $R S O$ right salpingo-oophorectomy, $B S O$ bilateral salpingooophorectomy, TVH total vaginal hysterectomy 
Final histopathology reported a normal appendix and bilateral sterile acute salpingitis and tubal abscesses. Fungal and gram stains from the specimens were negative.

\section{Discussion}

PATSS is a delayed complication of endometrial ablation, initially described in 1993 by Townsend et al. [1]. Most cases of PATSS discussed in the literature were complications of first-generation resectoscopic ablation procedures such as the rollerball endometrial ablation [1-8]. A $10 \%$ incidence of symptomatic hematometra and PATSS were diagnosed primarily after total rollerball endometrial ablation [5]. A thorough review of the literature revealed no documented cases of PATSS following NovaSure ${ }^{\circledR}$ endometrial ablation.

An extensive search on Ovid, PubMed, Cochrane, and Medline databases in the English language was performed. The search terms used were: "postablation tubal sterilization syndrome," "hydrosalpinx," "pyosalpinx," and "hematosalpinx" in combination with "NovaSure ${ }^{\circledR}$ " or "radiofrequency energy endometrial ablation" search terminologies. No direct matches were found. Novasure first received FDA approval for use in the USA on September 28, 2001 [9]. Manufacturer and User Facility Device Experience (MAUDE) adverse event reports on PATSS or PATSSlike symptoms with Novasure were last updated on March 31, 2012 [10]. A thorough review of the MAUDE database between this 11-year time period revealed four cases of PATSS-like symptoms attributed to Novasure ${ }^{\circledR}$, but none were available in print on any medical journal. Only one of these cases, case no. 2, was offered online publication in Obgyn.net [11]. There were two cases without mention of tubal ligation; therefore, the PATSS diagnosis is non-verifiable.

Table 1 shows published cases of PATSS documented by histopathology. Majority of cases occurred after rollerball endometrial ablation/resection technique [1-8], one case post-microwave endometrial ablation [12] and one case after thermal balloon endometrial ablation [13].

\section{Conclusion}

There is a renewed interest in endometrial ablation techniques because of the shorter operative times, ease of use, and less invasive nature of the second-generation endometrial ablation devices. There are currently four FDA-approved, nonresectoscopic endometrial ablation devices in the market, namely: ThermaChoice ${ }^{\mathbb{B}}$ uterine balloon therapy, Genesys Hydro ThermAblator $\left(\right.$ HTA $\left.^{\circledR}\right)$, Her Option ${ }^{\mathrm{TM}}$ cryoablation, and NovaSure ${ }^{\circledR}$ endometrial ablation systems. Different energy sources used include heated fluid either inside a balloon or circulating freely inside the endometrial cavity, cryoablation, and radiofrequency electricity [14]. The microwave endometrial ablation device is currently unavailable in the USA.

PATSS is characterized by cyclic pelvic pain with hydrosalpinx, hematosalpinx, and tubal inflammation. New-onset cyclic pelvic pain in women with previous tubal ligation following hysteroscopic endometrial ablation is suspect for PATSS. The cornual endometrium persists and remains active after using global endometrial ablation devices. The endometrial cells regenerate, shed, and collect in these areas, and then bleed into the obstructed fallopian tubes, causing tubal distention and pelvic pain. The pathophysiology appears to be a progression of the disease process. The hydrosalpinx or hematosalpinx associated with PATSS could become chronically infected leading to a tubo-ovarian abscess as seen in the second case report.

The incidence of PATSS has increased over the past several years with a current incidence of $8-33 \%$ [15]. The diagnosis of PATSS requires further expansion and discussion and is one that is difficult to make. The tendency of the cornual hematometra to resorb during asymptomatic periods makes type and timing of imaging techniques critical. MRI may be a more sensitive and diagnostic modality, and should be performed during a patient's menstrual cycle for better visualization of the cornual hematometra [16].

Operative laparoscopy with bilateral salpingectomy is recommended even in patients with unilateral hydrosalpinx to prevent recurrence and achieve complete resolution of symptoms. Because of possible resorption of collected blood, pathology may be unable to diagnose hematosalpinx. It is important to perform the surgeries during the symptomatic time period in order to have histopathological evidence of disease [16]. Early recognition of the symptoms of PATSS provides timely diagnosis and management of complications associated with endometrial ablation.

Conflict of interest The authors report no conflicts of interest. The authors alone are responsible for the content and writing of the paper.

\section{References}

1. Townsend DE, McCausland V, McCausland A, Fields G, Kauffman K (2003) Post-ablation-tubal sterilization syndrome. Obstet Gynecol $82: 422-424$

2. Martin JE, Inglis TCM (2005) A case of post-ablation-tubal sterilization syndrome. Gynecol Surg 2:205-207

3. Bae IH, Pagedas A, Perkins H, Bae D (1996) Post ablation-tubal sterilization syndrome. J Am Assoc Gynecol Laparosc 3:435-438

4. Webb JC, Bush MR, Wood MD, Gordon SP (1996) Hematosalpinx with pelvic pain after endometrial ablation confirms the postablation-tubal sterilization syndrome. J Am Assoc Gynecol Laparosc 3:419-421 
5. McCausland AM, McCausland VM (2002) Frequency of symptomatic cornual hematometra and postablation tubal sterilization syndrome after total rollerball endometrial ablation: a 10-year follow-up. Am J Obstet Gynecol 186:1274-1283

6. Huang SY, Huang SY, Wang CJ, Han CM, Lee CL, Soong YK (2008) Postablation tubal sterilization syndrome. Taiwan J Obstet Gynecol 47:120-122

7. Unger JB, Meeks GR (1996) Hysterectomy after endometrial ablation. Am J Obstet Gynecol 175(6):1432-1436

8. Turnbull LW, Bowsley SJ, Horsman A (1997) Magnetic resonance imaging of the uterus after endometrial resection. Br J Obstet Gynaecol 104:934-938

9. Novacept, Inc (2001) Premarket approval application, P010013: summary of safety and effectiveness data: NovaSure ${ }^{\mathrm{TM}}$ impedance controlled endometrial ablation

10. US Department of Health and Human Services, US Food and Drug Administration (2011) MAUDE - manufacturer and user facility device experience. Last update 3/31/12. At: http://www.accessdata.fda. gov/scripts/cdrh/cfdocs/cfmaude/search.cfm
11. Tam T, Jirschele K, Lombard E (2009) Post-ablation tubal sterilization syndrome following radiofrequency electricity endometrial ablation. OBGYN.net Laparoscopy \& Hysteroscopy http://www.obgyn.net/ hysteroscopy/hysteroscopy.asp?page=/hysteroscopy/articles/patss. Accessed 19 February 2012

12. Chukwujama AE, Khalifa L, Mensah PK (2007) Post-ablation tubal sterilization syndrome following microwave endometrial ablation. Gynecol Surg 4:141-143

13. Leung PL, Yuen PM (2006) Post ablation tubal sterilization syndrome following thermal balloon ablation. Acta Obstet Gynecol Scand 85:504-505

14. American College of Obstetricians and Gynecologists (2007) ACOG Practice Bulletin Number: no. 81: endometrial ablation. Obstet Gynecol 109(5):1233-1248

15. McCausland AM, McCausland VM (2007) Long-term complications of endometrial ablation. J Minim Invasive Gynecol 14:399

16. McCausland AM, McCausland VM (2010) Long-term complications of minimally invasive endometrial ablation devices. J Gynecol Surg 26(2):133-149 